\title{
PENERAPAN 7 LANGKAH MENUJU KESELAMATAN PASIEN DI PUSKESMAS
}

\author{
SRI HARVITA SARI MARPAUNG/181101125
}

Sriharvitaaasm11@gmail.com

\begin{abstract}
ABSTRAK
Latar belakang : Keselamatan pasien puskesmas adalah suatu sistem dimana puskesmas membuat asuhan pasien lebih aman salah satunya adalah melalui penerapan 7 langkah menuju keselamatan pasien.

Tujuan : Terciptanya budaya keselamatan pasien di puskesmas, meningkatkan akuntabilitas Puskesmas terhadap pasien dan masyarakat, menurunnya kejadian tidak diharapkan (KTD) di Puskesmas, terlaksananya program-program pencegahan sehingga tidak terjadi pengulangan kejadian tidak diharapkan.

Metode : literature riview berdasarkan teks book, jurnal, e-book (10 tahun terakhir) dengan cara menganalisis, eksplorasi sumber dan kajian bebas.

Hasil : penerapan langkah - langkah menuju keselamatan pasien adalah untuk meningkatkan kesehatan pasien dan dapat menerapkan menerapkan 7 langkah menuju keselamatan pasien di puskesmas sehingga dapat meningkatkan mutu pelayanan dan meningkatkan akuntabilitasi puskesmas.

Pembahasan : Standar dan kriteria 7 langkah menuju keselamatan pasien.

Kesimpulan : Dalam pencapaian keselamatan pasien di puskesmas dapat diterapkan melalui tahapan 7 langkah - langkah menuju keselamatan pasien yang bertujuan untuk meningkatkan mutu pelayanan dan akuntabilitas puskesmas.
\end{abstract}

Kata kunci : puskesmas, keselamatan pasien, 7 langkah menuju keselamatan pasien.

\section{LATAR BELAKANG}

Keselamatan pasien puskesmas adalah suatu sistem dimana puskesmas membuat asuhan pasien lebih aman yang meliputi asesmen risiko, identifikasi dan pengelolaan hal yang berhubungan dengan risiko pasien, pelaporan dan analisis insiden, kemampuan belajar dari insiden dan tindak lanjutnya serta implementasi solusi untuk meminimalkan timbulnya risiko dan mencegah terjadinya cedera yang disebabkan oleh kesalahan akibat melaksanakan suatu tindakan atau tidak mengambil tindakan yang seharusnya diambil.

Ada lima isu penting yang terkait dengan keselamatan (safety) yaitu: keselamatan pasien (patient safety), keselamatan pekerja atau petugas kesehatan, keselamatan bangunan dan peralatan di Puskesmas yang bisa 
berdampak terhadap keselamatan pasien dan petugas, keselamatan lingkungan (green productivity) yang berdampak terhadap pencemaran lingkungan dan keselamatan "bisnis" yang terkait dengan kelangsungan hidup Puskesmas. Kelima aspek keselamatan tersebut sangatlah penting untuk dilaksanakan.Namun harus diakui kegiatan institusi kesehatan dapat berjalan apabila ada pasien oleh karena itu keselamatan pasien merupakan prioritas utama untuk dilaksanakan dan hal tersebut terkait dengan isu mutu dan citra puskesmas. Harus diakui, pelayanan kesehatan pada dasarnya adalah untuk menyelamatkan pasien sesuai dengan yang diucapkan Hiprocrates kira-kira 2400 tahun yang lalu yaitu Primum, non nocere (First, do no harm).

Namun diakui dengan semakin berkembangnya ilmu dan teknologi pelayanan kesehatan menjadi semakin kompleks dan berpotensi terjadinya Kejadian Tidak Diharapkan - KTD (Adverse event) apabila tidak dilakukan dengan hati-hati. Di puskesmas terdapat ratusan macam obat, ratusan tes dan prosedur, banyak alat dengan teknologinya, bermacam jenis tenaga profesi dan non profesi yang siap memberikan pelayanan pasien 24 jam. Keberagaman dan kerutinan pelayanan tersebut apabila tidak dikelola dengan baik dapat terjadi KTD.

Mengingat keselamatan pasien sudah menjadi tuntutan masyarakat maka pelaksanaan program keselamatan pasien perlu dilakukan. Karena itu diperlukan acuan yang jelas untuk melaksanakan keselamatan pasien tersebut.

\section{TUJUAN}

Tujuan dari penulisan ini adalah untuk :

1. Terciptanya budaya keselamatan pasien di puskesmas

2. Meningkatnya akuntabilitas Puskesmas terhadap pasien dan masyarakat

3. Menurunnya kejadian tidak diharapkan (KTD) di Puskesmas.

4. Terlaksananya program-program pencegahan sehingga tidak terjadi pengulangan kejadian tidak diharapkan.

\section{METODE}


Metode yang digunakan dalam penulisan ini menggunakan literature riview berdasarkan teks book, jurnal, $e$ book (10 tahun terakhir) dengan cara menganalisis, eksplorasi sumber dan kajian bebas.

\section{HASIL}

Hasil yang akan didapatkan dari hasil penulisan ini adalah penerapan langkah - langkah menuju keselamatan pasien adalah untuk meningkatkan kesehatan pasien dan dapat menerapkan menerapkan 7 langkah menuju keselamatan pasien di puskesmas sehingga dapat meningkatkan mutu pelayanan dan meningkatkan akuntabilitasi puskesmas.

\section{PEMBAHASAN}

Standar keselamatan pasien tersebut terdiri dari tujuh standar yaitu :

\section{Hak pasien}

\section{Standar :}

Pasien dan keluarganya mempunyai hak untuk mendapatkan informasi tentang rencana dan hasil pelayanan termasuk kemungkinan terjadinya Kejadian Tidak Diharapkan (KTD).

\section{Kriteria :}

a. Harus ada dokter penanggung jawab pelayanan. b. Dokter penanggung jawab pelayanan wajib membuat rencana pelayanan

c. Dokter penanggung jawab pelayanan wajib memberikan penjelasan secara jelas dan benar kepada pasien dan keluarganya tentang rencana dan hasil pelayanan, pengobatan atau prosedur untuk pasien termasuk kemungkinan terjadinya Kejadian Tidak Diharapkan.

2. Mendidik pasien dan keluarga

\section{Standar :}

Puskesmas harus mendidik pasien dan keluarganya tentang kewajiban dan tanggung jawab pasien dalam asuhan pasien

\section{Kriteria :}

Keselamatan dalam pemberian pelayanan dapat ditingkatkan dengan keterlibatan pasien yang merupakan partner dalam proses pelayanan. Karena itu, di puskesmas harus ada sistem dan mekanisme mendidik pasien dan keluarganya tentang kewajiban dan tanggung jawab pasien dalam asuhan pasien. 
Dengan pendidikan tersebut diharapkan pasien dan keluarga dapat :

a. Memberikan informasi yang benar, jelas, lengkap dan jujur.

b. Mengetahui kewajiban dan tanggung jawab pasien dan keluarga.

c. Mengajukan pertanyaanpertanyaan untuk hal yang tidak dimengerti

d. Memahami dan menerima konsekuensi pelayanan.

e. Mematuhi instruksi dan menghormati peraturan puskesmas.

f. Memperlihatkan sikap menghormati dan tenggang rasa.

g. Memenuhi kewajiban finansial yang disepakati.

3. Keselamatan pasien dan kesinambungan pelayanan

\section{Standar :}

Puskesmas menjamin kesinambungan pelayanan dan menjamin koordinasi antar tenaga dan antar unit pelayanan.

\section{Kriteria :}

a. Terdapat koordinasi pelayanan secara menyeluruh mulai dari saat pasien masuk, pemeriksaan,diagnosis,

perencanaan pelayanan, tindakan pengobatan, rujukan dan saat pasien keluar dariPuskesmas.

b. Terdapat koordinasi pelayanan yang disesuaikan dengan kebutuhan pasien dan kelayakansumber daya secara berkesinambungan sehingga pada seluruh tahap pelayanan transisi antarunit pelayanan dapat berjalan baik dan lancar.

c. Terdapat koordinasi pelayanan yang mencakup peningkatan komunikasi untuk memfasilitasidukungan

keluarga, pelayanan keperawatan, pelayanan sosial, konsultasi dan rujukan,pelayanan kesehatan primer dan tindak lanjut lainnya.

d. Terdapat komunikasi dan transfer informasi antar profesi kesehatan sehingga dapat tercapainyaproses koordinasi tanpa hambatan, aman dan efektif.

4. Penggunaan metoda-metoda peningkatan kinerja untuk 
melakukan evaluasi dan program peningkatan keselamatan pasien.

\section{Standar :}

Puskesmas harus mendesign proses baru atau memperbaiki proses yang ada, memonitor danmengevaluasi kinerja melalui pengumpulan data, menganalisis secara intensif Kejadian TidakDiharapkan, dan melakukan perubahan untuk meningkatkan kinerja serta keselamatan pasien.

\section{Kriteria :}

a. Setiap puskesmas harus melakukan proses perancangan (design) yang baik, mengacu pada visi, misi, dan tujuan puskesmas, kebutuhan pasien, petugas pelayanan kesehatan, kaidah klinis terkini,praktik bisnis yang sehat, dan faktorfaktor lain yang berpotensi risiko bagi pasien sesuai dengan”Tujuh Langkah Menuju Keselamatan Pasien Puskesmas".

b. Setiap Puskesmas harus melakukan pengumpulan data kinerja yang antara lain terkait dengan :pelaporan insiden, akreditasi, manajemen risiko, utilisasi, mutu pelayanan, keuangan.

c. Setiap Puskesmas harus melakukan evaluasi intensif terkait dengan semua Kejadian TidakDiharapkan, dan secara proaktif melakukan evaluasi satu proses kasus risiko tinggi.

d. Setiap Puskesmas harus menggunakan semua data dan informasi hasil analisis untuk menentukanperubahan sistem yang diperlukan, agar kinerja dan keselamatan pasien terjamin.

5. Peran kepemimpinan dalam meningkatkan keselamatan pasien

\section{Standar :}

- Pimpinan mendorong dan menjamin implementasi program keselamatan pasien secara terintegrasidalam organisasi melalui penerapan "Tujuh Langkah Menuju Keselamatan Pasien Puskesmas ,

- Pimpinan menjamin berlangsungnya program proaktif untuk identifikasi risiko 
keselamatan pasiendan program menekan atau mengurangi Kejadian Tidak Diharapkan.

- Pimpinan mendorong dan menumbuhkan komunikasi dan koordinasi antar unit dan individu berkaitandengan pengambilan keputusan tentang keselamatan pasien.

- Pimpinan mengalokasikan sumber daya yang adekuat untuk mengukur, mengkaji, dan meningkatkankinerja Puskesmas serta meningkatkan keselamatan pasien.

- Pimpinan mengukur dan mengkaji efektifitas kontribusinya dalam meningkatkan kinerja Puskesmas dan keselamatan pasien.

\section{Kriteria :}

a. Terdapat tim antar disiplin untuk mengelola program keselamatan pasien.

b. Tersedia program proaktif untuk identifikasi risiko keselamatan dan program meminimalkaninsiden, yang mencakup jenis-jenis Kejadian yang memerlukan perhatian, mulai dari "KejadianNyaris
Cedera" (Near miss) sampai dengan "Kejadian Tidak Diharapkan' (Adverse event).

c. Tersedia mekanisme kerja untuk menjamin bahwa semua komponen dari

Puskesmasterintegrasi dan berpartisipasi dalam program keselamatan pasien.

d. Tersedia prosedur "cepattanggap" terhadap insiden, termasuk asuhan kepada pasien yangterkena musibah, membatasi risiko pada orang lain dan penyampaian informasi yang benar danjelas untuk keperluan analisis.

e. Tersedia mekanisme pelaporan internal dan eksternal berkaitan dengan insiden termasukpenyediaan informasi yang benar dan jelas tentang Analisis Akar Masalah (RCA) "KejadianNyaris Cedera" (Near miss) dan 'Kejadian Sentinel' pada saat program keselamatan pasienmulai dilaksanakan.

f. Tersedia mekanisme untuk menangani berbagai jenis insiden, misalnya menangani "KejadianSentinel” (Sentinel Event) atau kegiatan proaktif 
untuk memperkecil risiko, termasuk mekanismeuntuk mendukung staf dalam kaitan dengan "Kejadian Sentinel”.

g. Terdapat kolaborasi dan komunikasi terbuka secara sukarela antar unit dan antar pengelolapelayanan di dalam Puskesmas dengan pendekatan antar disiplin.

h. Tersedia sumber daya dan sistem informasi yang dibutuhkan dalam kegiatan perbaikan kinerja Puskesmas dan perbaikan keselamatan pasien, termasuk evaluasi berkala terhadap kecukupansumber daya tersebut.

i. Tersedia sasaran terukur, dan pengumpulan informasi menggunakan kriteria objektif untuk mengevaluasi efektivitas perbaikan kinerja Puskesmas dan keselamatan pasien, termasukrencana tindak lanjut dan implementasinya.

6. Mendidik staf tentang keselamatan pasien

Standar :
- Puskesmas memiliki proses pendidikan, pelatihan dan orientasi untuk setiap jabatan mencakupketerkaitan jabatan dengan keselamatan pasien secara jelas

- Puskesmas menyelenggarakan pendidikan dan pelatihan yang berkelanjutan untuk meningkatkandan memelihara kompetensi staf serta mendukung pendekatan interdisiplin dalam pelayanan pasien.

\section{Kriteria :}

a. Setiap Puskesmas harus memiliki program pendidikan, pelatihan dan orientasi bagi staf baruyang memuat topik keselamatan pasien sesuai dengan tugasnya masingmasing.

b. Setiap Puskesmas harus mengintegrasikan topik keselamatan pasien dalam setiap kegiatan inservicetraining dan memberi pedoman yang jelas tentang pelaporan insiden.

c. Setiap Puskesmas harus menyelenggarakan pelatihan tentang kerjasama kelompok (teamwork)guna mendukung 
pendekatan interdisiplin dan

kolaboratif dalam rangka

melayani pasien.

7. Komunikasi merupakan kunci bagi staf untuk mencapai keselamatan pasien.

\section{Standar :}

- Puskesmas merencanakan dan mendesain proses manajemen informasi keselamatan pasien untuk memenuhi kebutuhan informasi internal dan eksternal.

- Transmisi data dan informasi harus tepat waktu dan akurat.

\section{Kriteria :}

a. Perlu disediakan anggaran untuk merencanakan dan mendesain proses manajemen untukmemperoleh data dan informasi tentang hal-hal terkait dengan keselamatan pasien.

Anggraini, A. N. Dkk. (2018). Hubungan Implementasi IPSG (International Patient Safety Goals) dengan Kepuasan Pasien di Puskesmas Kasihan I Bantul. (Indonesian Journal of Hospital Administration), Vol. 1, No. 1, Tahun 2018. b. Tersedia mekanisme identifikasi masalah dan kendala komunikasi untuk merevisi manajemeninformasi yang ada.

\section{KESIMPULAN}

Penerapan keselamatan pasien di puskesmas merupakan salah satu prioritas utama puskesmas dalam memberikan pelayanan kepada pasien maupun masyarakat, oleh sebab itu puskesmas perlu memiliki dasar untuk menerapkan program keselamatan pasien salah satunya adalah 7 langkah -langkah menuju keselamatan pasien sehingga dalam proses pelayanan layanan yang diberikan adalah layanan yang bermutu sehingga dapat meningkatkan derajat kesehatan pasien dan juga untuk meningkatan akuntabilitasi puskesmas tersebut.

\section{REFERENSI}

Azrul, A. (1996). Menuju Pelayanan Kesehatan yang Bermutu. Jakarta : Salemba Medika.

Asmadi. (2008). Konsep Dasar Keperawatan. Jakarta : EGC 
Cahyono, J. B. S. (2012). Membangun

Budaya Keselamatan Pasien dalam Praktek Kedokteran. Yogyakarta

Deswani. (2009). Proses Keperawatan dan Berpikir Kritis. Jakarta : Salemba Medika

Departemen Kesehatan RI. (2006). Panduan Nasional Keselamatan Pasien Rumah sakit. Jakarta : Depkes RI

Gede, M. A. A. (2011). Manajemen Mutu Pelayanan Kesehatan. Jakarta : EGC

Harus, B. D. (2015). Pengetahuan Perawat tentang Keselamatan Pasien dengan Pelaksanaan Prosedur Keselamatan Pasien Rumah Sakit (KPRS) di Rumah Sakit Panti Waluya Sawahan Malang. (Jurnal CARE), Vol. 3, No. 1, Tahun 2015.

Kemenkes RI. (2013). Panduan Stanley, M. (2006). Buku Ajar Keselamatan Pasien. Jakarta
Marquis, B.L. (2010). Kepemimpinan dan Manajemen Keperawatan: Teori dan Aplikasi. Jakarta : EGC

Nursalam. (2011). Manajemen Keperawatan: Aplikasi dalam Keperawatan Profesional, ed.3. Jakarta : Salemba Medika.

Perry \& Potter. (2005). Fundamental Keperawatan : Konsep Proses dan Praktek. Jakarta : EGC

Rivai F, Sidin A.I, Kartika I. (2016). Faktor yang Berhubungan dengan Implementasin Keslamatan Pasien di RSUD Ajjappannge Soppeng Tahun 2015. Volume 05

Simamora, R.H. (2018). Buku Ajar Keselamatan Pasien Melalui Timbang Terima Pasien Berbasis Komunikasi Efektif: SBAR Keperawatan Gerontik. Edisi 2. Jakarta: EGC 